\title{
Tenofovir Induced Acute Kidney Injury in a Patient with Unilateral Renal Agenesis Despite Initially Non-IMPAIRED RENAL FunCTION
}

\author{
B. T. Schleenvoigt, A. Stallmach, M. W. Pletz
}

Division of Gastroenterology, Hepatology and Infectious Diseases, Jena University Hospital, Jena, Germany

\section{Abstract}

Nephrotoxicity is observed in $1.6 \%$ of patients treated with tenofovir disoproxil fumarat (Fux 2007).

\section{CASE RePort}

We report a 37 year old late presenting HIV positive male patient. He was admitted with wasting, chronic diarrhoea and oesophageal candidiasis. Serology confirmed HIV-1 infection, viral load was 55.000 copies /mL(Abbott Realtime HIV-1, RT-PCR). CD4 + cells were $77 / \mu \mathrm{L}$, and the CD4/CD8 ratio was 0.11 . An agenesis of the right kidney with a contra-lateral hypertrophy was detected by abdominal ultrasound. However, normal values for creatinine $(75 \mu \mathrm{mol} / \mathrm{L})$ and urea (5.6 mmol/L) did not suggest an impaired renal function (GFR-MDRD $108 \mathrm{~mL} / \mathrm{min}$ ). In addition, history revealed no risk factors for renal insufficiency (no diabetes mellitus, non-smoker, no hypertension). Concomitant medication did not contain drugs in appropriate doses with known high potential for nephrotoxicity (trimethoprim $160 \mathrm{mg}$ three times per week, sulfamethoxazol $800 \mathrm{mg}$ three times per week, folic acid 5 $\mathrm{mg}$ twice daily, diflucan $100 \mathrm{mg}$ daily, ceftriaxon $2 \mathrm{~g}$ daily, pantoprazol $40 \mathrm{mg}$ twice daily, enoxaparin $40 \mathrm{mg}$ s.c. daily, mirtazapin $15 \mathrm{mg}$ daily). Because of the high viral load and the detoriated clinical condition we decided to start an antiretroviral regimen as soon a possible. Since HLA-B5701 test result was pending, Abacavir was not an option and we started with tenofovir, emtricitabin plus raltegravir to achieve fast reduction of viral load (Lennox 2009). An extensive literature research did not reveal any data on tenofovir in patients with renal agenesis.

Two days after initiation of ART laboratory monitoring of the renal function showed steadily increasing values for urea and creatinine reaching maximal levels of $14.2 \mathrm{mmol} / \mathrm{L}$ and $172 \mu \mathrm{mol} / 1$, respectively on day 6 despite intravenous volume substitution (GFR-MDRD $41.5 \mathrm{~mL} / \mathrm{min}$ ). The patient developed acute kidney injury according to the RIFLE criteria (Bellomo 2004) When HLA-B5701 was tested to be negative; the NRTI backbone was switched from tenofovir plus emtricitabin to abacavir plus lamivudin. After discontinuation of tenofovir renal parameters restored within 36 hours to baseline values (GFR-MDRD $104.5 \mathrm{~mL} / \mathrm{min}$ ) and remained at normal values during the further curse.

The most frequent mechanism of tenofovir induced kidney failure is supposed to be tubular necrosis due to mitochondrial toxicity. Tubular necrosis can result in hypophosphataemia, glucosuria, and in a decrease of
GFR due to intrarenal feed back mechanisms (e.g. by vasoconstriction of the Vas afferens). A recent renal biopsy study in 13 cases of tenofovir nephrotoxicity revealed toxic acute tubular necrosis, with distinctive proximal tubular eosinophilic inclusions representing giant mitochondria visible by light microscopy (Herlitz 2010). Electron microscopy showed mitochondrial enlargement, depletion, and dysmorphic changes. As in our case significant recovery of renal function occurred in all these patients after discontinuation of tenofovir, including in four patients who required transient hemodialysis.

Since its introduction in 2001 the nucleotide analogue tenofovir is one of the most frequently used substances in HIV treatment. Our case showed that tenofovir can induce a renal damage in patients with renal agenesis despite initially non-impaired renal function. Due to our experience we suggest that tenofovir should not be used in these patients regardless of a normal renal function.

\section{REFERENCES}

Bellomo R, Ronco C, Kellum JA, et al. Acute renal failure definition, outcome measures, animal models, fluid therapy and information technology needs: the Second International Consensus Conference of the Acute Dialysis Quality Initiative (ADQI) Group. Crit Care. 2004 Aug;8(4):R204-12. Epub 2004 May 24.

Fux CA, Simcock M, Wolbers M, et al. Tenofovir use is associated with a reduction in calculated glomerular filtration rates in the Swiss HIV Cohort Study. Antivir Ther. 2007;12(8):1165-73.

Lennox JL, DeJesus E, Lazzarin A, et al. Safety and efficacy of raltegravir-based versus efavirenz-based combination therapy in treatment-naive patients with HIV-1 infection: a multicentre, double-blind randomised controlled trial. Lancet. 2009 Sep 5;374(9692):796-806. Epub 2009 Aug 3.

Herlitz LC, Mohan S, Stokes MB, Radhakrishnan J, D'Agati VD, Markowitz GS. Tenofovir nephrotoxicity: acute tubular necrosis with distinctive clinical, pathological, and mitochondrial abnormalities. Kidney Int. 2010 Dec;78(11):1171-7. Epub 2010 Sep 1.

Received: March 29, 2011 / Accepted: May 17, 2011

Address for correspondence:

Prof. Dr. Mathias W. Pletz

Abt. für Gastroenterologie, Hepatologie und Infektiologie

Universitätsklinikum Jena

Erlanger Allee 101

07740 Jena

Germany

E-mail: mathias.pletz@med.uni-jena.de 